\title{
REDUCTION IN OVERALL SURVIVAL OF WOMEN WITH METASTATIC BREAST CANCER IN LOW- AND MIDDLE-INCOME COUNTRIES: A REFLECTION OF LACK OF ACCESS?
}

\author{
Leonardo R. Soares ${ }^{1}$, Ruffo Freitas-Junior¹, Edesio Martins' ${ }^{1}$, José C. Oliveira'1, Maria P. Curado \\ ${ }^{1}$ Population-Based Cancer Registry of Goiânia, Goiás Association to Cancer Combat - Goiânia (GO), Brazil.
}

Objective: The objective of the present study was to analyse the overall survival of women diagnosed with metastatic breast cancer (MBC) in the city of Goiânia, Brazil. Methods: Cases were identified in the Population-Based Cancer Registry of Goiânia, Brazil, from 1995 to 2011. All women with metastatic disease were included in the study. Clinical and demographic characteristics of the sample were analysed, as well as information related to the diagnosis and treatment of the disease. The variables that are not systematically recorded were collected directly from the medical records. Overall survival was divided into analyses of 60 and 120 months of follow-up. Results: Two hundred and seventy-seven women were included, whose mean age at diagnosis was 54.7 ( \pm 14.5$)$ years. Overall survival at 60 and 120 months was 19,9 and 7,3\%, respectively. In the univariate analysis, the following variables were significant: staging (T); histological type; histological grade; oestrogen receptor; progesterone receptor; tumour phenotype; type of health care; performing breast surgery; initial site of metastasis; and surgery for resection of metastasis. Among patients with hormone receptor positive (HR+) tumours, there was no difference according to the treatment received in the first line (chemotherapy versus endocrine therapy). In the 10-year multivariate analysis, adjusted for the expression of hormone receptors, significant values were observed for the variables tumour grade $(\mathrm{p}=0.02)$, financing source $(\mathrm{p}=0.02)$, presence of breast surgery $(0.001)$, and initial site of metastasis $(\mathrm{p}=0.03)$. Conclusion: This is the first population-based study addressing MBC in Brazil. Overall survival in this population was about $50 \%$ lower than in developed countries. Access to private health care and surgery for resection of the primary tumour proved to be significant in predicting overall survival in five years. 